\title{
Correction to: On the hermeneutics of screen time
}

\author{
Jesper Aagaard ${ }^{1} \cdot$ Emma Steninge $^{1} \cdot$ Yibin Zhang $^{1}$
}

Accepted: 31 May 2021

๑) Springer-Verlag London Ltd., part of Springer Nature 2021

\section{Correction to: AI \& SOCIETY}

https://doi.org/10.1007/s00146-021-01223-y

In the Original publication of the article the revised date was erroneously published as: 20 August 2017 the correct date is: 20 August 2020.

The original article has been updated.

Publisher's Note Springer Nature remains neutral with regard to jurisdictional claims in published maps and institutional affiliations.

The original article can be found online at https://doi.org/10.1007/ s00146-021-01223-y.

$\triangle$ Jesper Aagaard jaagaard@psy.au.dk

Emma Steninge

201509245@post.au.dk

Yibin Zhang

yibin@psy.au.dk

1 Department of Psychology and Behavioral Sciences, Aarhus University, 8000 Aarhus C, Denmark 